\title{
THE
}

3-1-2015

\section{A Marine Autonomous Surface Craft for Long-Duration, Spatially Explicit, Multidisciplinary Water Column Sampling in Coastal and Estuarine Systems}

Daniel L. Codiga

University of Rhode Island, dcodiga@uri.edu

Follow this and additional works at: https://digitalcommons.uri.edu/gsofacpubs

Terms of Use

All rights reserved under copyright.

\section{Citation/Publisher Attribution}

Daniel L. Codiga. (2015). "A Marine Autonomous Surface Craft for Long-Duration, Spatially Explicit, Multidisciplinary Water Column Sampling in Coastal and Estuarine Systems." Journal of Atmospheric and Oceanic Technology. 32(3): 627-641.

Available at: http://dx.doi.org/10.1175/JTECH-D-14-00171.1

This Article is brought to you for free and open access by the Graduate School of Oceanography at DigitalCommons@URI. It has been accepted for inclusion in Graduate School of Oceanography Faculty Publications by an authorized administrator of DigitalCommons@URI. For more information, please contact digitalcommons-group@uri.edu. 


\title{
A Marine Autonomous Surface Craft for Long-Duration, Spatially Explicit, Multidisciplinary Water Column Sampling in Coastal and Estuarine Systems
}

\author{
DANIEL L. CODIGA \\ Graduate School of Oceanography, University of Rhode Island, Narragansett, Rhode Island
}

(Manuscript received 28 August 2014, in final form 26 November 2014)

\begin{abstract}
The Surveying Coastal Ocean Autonomous Profiler (SCOAP) is a large catamaran marine autonomous surface craft (MASC) for unattended weeks-long, spatially explicit, multidisciplinary oceanographic water column profile sampling in coastal/estuarine waterbodies. Material transport rates/pathways, crucial to understanding these ecosystems, are typically poorly known. SCOAP addresses demanding spatiotemporal sampling needs and operational challenges (strong currents, open coastal sea states, complex bathymetry, heavy vessel traffic). Its large size (11-m length, $5-\mathrm{m}$ beam) provides seaworthiness/stability. The average speed of $2.5 \mathrm{~m} \mathrm{~s}^{-1}$ meets the representative goal to traverse an $18-\mathrm{km}$ transect, sampling $10 \mathrm{~min}$ at each of 10 stations $2 \mathrm{~km}$ apart, nominally 4 times daily. Efficient hulls and a diesel-electric energy system can provide the needed endurance. The U.S. Coast Guard guidelines are followed: lighting, code flags, the Automatic Identification System (AIS), and collision avoidance regulations (COLREGs)-based collision avoidance (CA) by onboard autonomy software. Large energy reserves obviate low-power optimization of sensors, enabling truly multidisciplinary sampling, and provide on-demand propulsion for effective CA. Vessel stability facilitates high-quality current profile observations and will aid engineering/operation of the planned winched profiling system, performance of an anticipated radar system to detect/track non-AIS vessels, and potential research-quality meteorological sensor operation. A Narragansett Bay test deployment, attended by an escort vessel, met design goals; an unattended open coastal deployment is planned for Rhode Island Sound. Scientific and operational strengths of large catamaran MASCs suggest they could be an important costeffective complement to other sampling platforms (e.g., improved spatiotemporal coverage and resolution, extending farther inshore, with a broader range of sensors, compared to underwater gliders) in coastal/ estuarine waters.
\end{abstract}

\section{Introduction}

Marine autonomous surface crafts (MASCs), or unmanned surface vessels (USVs) as their precursors traditionally have been known, bring potential advantages as mobile oceanographic sampling platforms for longduration (up to weeks at a time) multidisciplinary water column sampling in shallow-water conditions. Coastal and estuarine systems commonly have strong tidal currents and complex bathymetric and/or coastline geometries, as well as intense vessel traffic that must be actively avoided. A MASC of suitably large size can be equipped with sufficient energy resources for sustained propulsion strong enough to overcome tidal currents. It can straightforwardly host a hull-mounted acoustic Doppler current profiler

Corresponding author address: Daniel L. Codiga, Graduate School of Oceanography, University of Rhode Island, 215 S. Ferry Rd., Narragansett, RI 02882.

E-mail: d.codiga@gso.uri.edu
(ADCP) to measure water column current profiles and can feasibly host a winched profiling system to measure multidisciplinary oceanographic parameters (e.g., temperature, salinity, chlorophyll fluorescence, dissolved oxygen, turbidity, nutrients, optics, etc.) throughout the water column using available sensors without the need for them to be specially engineered for low-power operations or miniaturized form factor. Furthermore, the persistent surface presence of a MASC, if equipped with relatively strong ondemand propulsion, makes possible the use of onboard vessel detection devices and autonomous navigation systems to perform collision avoidance (CA) maneuvers.

A combination of rapidly advancing technologies is helping to open up the possibility for long-duration

Publisher's Note: This article was revised on 2 April 2015 to correct a misspelling of the author name Dabrowski in the reference Dabrowski et al. (2011), as well as its matching citation. 
MASC deployments. First, the Automatic Identification System (AIS) monitors ship traffic (vessel information such as position, speed, and heading) in real time from marine vessels, ground stations, and aircraft using very high frequency (VHF) radio (Arroyo 2011). AIS is required on commercial vessels over 300 tons and all passenger vessels, and though not required on smaller vessels, it is being implemented on them increasingly. Equipping a MASC with AIS is straightforward and helps ensure it will be detected by other AIS-equipped vessels, and vice versa. Second, onboard autonomy software frameworks for robotic systems are suitable for MASCs and are developing quickly. Examples include Control Architecture for Robotic Agent Command and Sensing (CARACAS; e.g., Kuwata et al. 2011), the Teleo-Reactive Executive (T-Rex) architecture (Rajan et al. 2009), and the Mission Oriented Operating Suite with Interval Programming (MOOS-IvP) Helm (Benjamin et al. 2009). Capabilities of CA software have been demonstrated in simulations (e.g., Filimon 2013) and in controlled field tests (e.g., Benjamin et al. 2006; Kuwata et al. 2014), and are approaching the capability for compliance (e.g., Campbell et al. 2014) with collision avoidance regulations (COLREGs; U.S. Coast Guard 1999) required by the U.S. Coast Guard (CG) and internationally.

This paper describes the oceanographic field sampling needs that motivated development of a new MASC for coastal and estuarine waterbodies; the associated design process, including guiding criteria and outcomes in the final realized vessel, the Surveying Coastal Ocean Autonomous Profiler (SCOAP); and the results of an initial field deployment.

\section{A motivation for MASC sampling capabilities in coastal/estuarine waters}

\section{a. Importance of material transport}

Rates and pathways of horizontal transport of water and waterborne materials are recognized as fundamental drivers of ecosystem processes in shelf, coastal, and estuarine settings. Transport terms commonly dominate budgets constructed for dissolved and suspended materials to understand key biological, chemical, and sedimentary dynamics. Examples are plentiful. Volume transport sets water residence time, perhaps the most essential system attribute. Heat transport is central to temperature variations, a major control of biological activity. Salt transport sets the vertical and horizontal density gradients, which influence circulation patterns. Nutrient transport impacts the base of food webs and thus the productivity at many trophic levels. Transports of phytoplankton and zooplankton can influence bloom dynamics and determine the spreading of harmful algal blooms. In hypoxic systems, deep transport of dissolved oxygen can

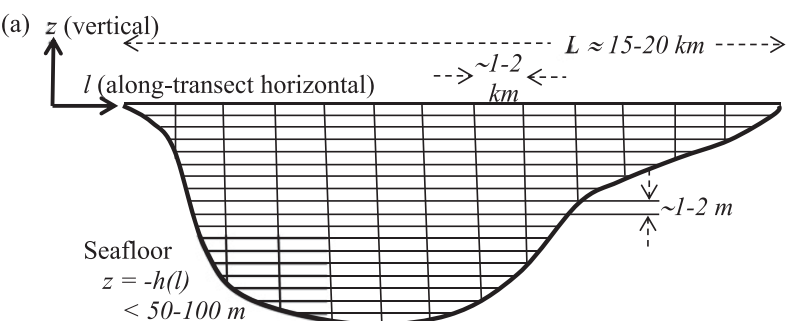

(b)

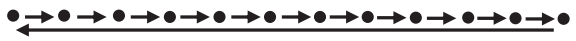

FIG. 1. (a) Transect vertical slice schematic showing MASC sampling: horizontal coverage $(L)$ and resolution $(\sim 1-2 \mathrm{~km})$ of stations, and vertical coverage ( 0 to $z=-h)$ and resolution $(\sim 1-$ $2 \mathrm{~m}$ ). (b) Repeat-transect survey: plan view depicting sequence of stations sampled. Each station (dots, corresponding to vertical lines above) is sampled while transiting in one direction (rightward in this case) and then the return leg (leftward) is completed without stopping.

be as important as vertical aeration through the air-sea interface. Transport of larvae determines life cycles and habitat connectivity for fish. Suspended sediment transport shapes erosion/deposition patterns. Transport of dissolved and particulate carbon across the continental margin is important to the global carbon cycle.

However, even in the best-examined shallow-water systems, our knowledge of transport often consists of crude inferences from indirect and incomplete information. This situation constitutes a major gap in coastal oceanographic science, significantly impeding progress in numerous interdisciplinary contexts. It stems largely from the challenging nature of sampling requirements to directly measure transports, particularly variability at long time scales.

\section{b. Sampling requirements to directly measure material transports through a transect}

Consider direct measurement of the horizontal transport, through a transect or a vertical section, of a generic material or property (Fig. 1a). Examples of important transects include a straight across-shelf line from shore to the shelf break, an arc on the inner shelf that bounds an inlet, or an across-estuary section. At a given time $t$, at each point in the along-transect coordinate $l$ from 0 to the length of the transect $L$, there is a vertical profile (vertical coordinate $z$, positive upward, 0 at sea surface) of the velocity component $U(z, t)$ perpendicular to the transect, and a depthvarying concentration $C(z, t)=M / V$ of the material or property, expressed as the amount $M$ per unit volume $V$. The transport $T(t)$ (dimensions $M$ per time) through the transect at $t$ is the product of the perpendicular velocity and the concentration, integrated over the water column and across the length of the transect, $T(t)=\int_{0}^{L} \int_{-h}^{0} U(z, t) C(z, t) d z d l$. For volume transport, unit concentration applies, and dimensions 
are volume per time. A full accounting would include, in addition to this advective transport, the diffusive/ dispersive component; for purposes of this discussion, the focus is on the advective component because its magnitude is dominant in many contexts, and it is generally more straightforward to measure.

First, observations are required of both (i) Earthreferenced horizontal vector velocities and (ii) property concentrations. Second, the measurements of each parameter must be made on similar spatial and temporal scales. Third, the spatial and temporal coverage and resolution required in typical coastal/estuarine settings is demanding. In the vertical, currents are commonly in opposite directions near the surface and bottom-for example, in coastal upwelling or estuarine exchange flow. Measurements thus must span the water column (up to $50-100 \mathrm{~m}$ ), where a resolution of about $1-2 \mathrm{~m}$ is typically needed. In the horizontal, currents can occur in bands of opposing directions. For example, at the opening to a sound or bay, water commonly moves in along one shore and out along the other. The breadth of these currents is set in principle by the internal deformation radius (usually defined based on flat-bottom, straight-coastline geophysical fluid dynamics; typically $5-10 \mathrm{~km}$ ), but in practice it is commonly more narrow due to the complicated geometry of coastline and bathymetric features on shorter scales $(1-2 \mathrm{~km})$. Furthermore, the position of such narrow currents often varies in time, shifting by at least several kilometers in response to wind and tidal variability. Consequently, to measure transport typically requires sampling a transect that spans at least $15-20 \mathrm{~km}$, with station spacing along the transect of no more than about $2 \mathrm{~km}$.

With respect to temporal coverage and resolution, the long-term mean transport is typically of the most interest, for its importance in determining material fate. However, variations in velocities and concentrations, and hence in the transport, on weather-band (wind driven, 3-10-day time-scale variability) and tidal time scales commonly have amplitudes comparable to or exceeding the long-term or residual mean. Therefore, the temporal sampling requirements are a duration and frequency sufficient to successfully separate the residual from the weather-band and tidal components. This usually means persistent sampling for at least a month, to capture several weather-band cycles, with a frequency of at least multiple times daily to help resolve tidal variations. Ideally, every tidal cycle could be resolved, but when this is not realistic, sampling a few times daily over at least a month can enable sufficient coverage of tidal phases to adequately determine the tidal component by harmonic fits. New tools for tidal analysis of records with irregularly distributed times and/or significant gaps (e.g., Codiga 2011) are valuable in this regard.
While the above-mentioned description of spatial and temporal variability has been in terms of currents, the conclusions apply largely unmodified to material/property concentrations. In summary, representative sampling requirements to make effective direct measurements of material transport through a shelf, coastal, or estuarine transect are (i) measurements of both Earth-referenced vector velocity and property concentrations; (ii) vertical coverage of the water column (up to 50-100-m depth) at about 1-2-m resolution; (iii) horizontal coverage of a 15-20-km transect resolved to about $2 \mathrm{~km}$ (about 8-10 stations); and (iv) temporal duration of at least a month, with at least 3-4 samples daily during the majority of the sampling period, in order to facilitate separation of tidal and nontidal variability.

\section{c. Repeat-transect sampling}

The above-mentioned discussion strongly motivates repeat-transect sampling (Fig. 1b) as the mode of MASC operation. Data are gathered at multiple locations (spatial coverage), over a long period of time (temporal coverage), by the MASC repeatedly traversing the same transect end to end. While estimates of the transport component perpendicular to the transect will be most straightforward, the transect can nonetheless be oriented arbitrarily relative to the typical flow patterns (see, e.g., Codiga and Aurin 2007). A given configuration of repeat-transect sampling is characterized by several parameters: the transect length and orientation, the number of stations, the average MASC speed, and the duration spent by the MASC at each station. Collection of water velocity profiles can be continuous by an ADCP while underway, or concentrated during periods of station keeping (holding position) at each station, when sampling water column profiles by winched profiler can occur. A typical duration on station would be 5-10 min to enable, for example, a multiparameter conductivity-temperature-depth (CTD) profile by a winch-equipped MASC. To create a dataset with sample times at each individual station that are as nearly uniformly distributed as possible, station keeping is only performed moving along the transect in one direction; stopping in both directions would lead to fundamentally different temporal distributions of samples from different stations, making the data more difficult to interpret and analyze. An operational advantage of repeat-transect sampling is the limited area of unattended operations, because the MASC can be either towed or escorted by a human-piloted vessel to and from the designated transect. This can help make obtaining CG permission for MASC operations more feasible. It also makes it more straightforward to inform other mariners where and when the MASC will operate unattended-for example, through the CG Local Notice to Mariners. 
The potential of long-duration MASC operations for oceanographic sampling is demonstrated by considering what a MASC could achieve through a repeat-transect deployment lasting multiple weeks. A MASC with an average speed of $5 \mathrm{kt}\left(\sim 2.5 \mathrm{~m} \mathrm{~s}^{-1}\right)$ could sample each of the 10 stations, $2 \mathrm{~km}$ apart on an 18 -km-long transect, for a 10-min duration at least 4 times a day. The average speed of $2.5 \mathrm{~m} \mathrm{~s}^{-1}$ is crucial to approach the needed temporal resolution at a given station; error analysis for transport estimates (Zhang et al. 2010) illustrates the importance of speed. Repeat-transect sampling with this specific set of parameters would generate a valuable spatially explicit oceanographic dataset that can address the goal of separating tidal and lower-frequency nontidal variability. This important need is rarely met well by spatially resolved observations, such as are collected by a research vessel, because typical survey durations are up to a few days at most at a given location. In effect, the data from such a MASC survey would approach that from an array of 10 moorings each with an ADCP and profiling multiparameter CTD system; the latter is infeasible due to both its high cost and interference with maritime operations in busy coastal waterways.

\section{SCOAP design process and outcome}

\section{a. Design goals}

The main SCOAP design goal is a capability to perform repeat-transect sampling, for purposes of estimating residual material transport as described above, during a monthlong unattended deployment in wave, wind, and current conditions of open coastal systems and exposed portions of large estuaries. The target sampling goals were as just explained (Fig. 1): an 18-km-long transect with 10 stations $2 \mathrm{~km}$ apart, to be traversed at an average speed of $2.5 \mathrm{~m} \mathrm{~s}^{-1}(\sim 5 \mathrm{kt})$ such that each station is sampled, for a duration of about $10 \mathrm{~min}$, nominally 4 times a day. Based on the scientific needs outlined above, a design goal is the capacity to host and provide power to oceanographic sensors, including a hull-mounted ADCP, and a winching system to lower and retrieve typical sensors (e.g., multiparameter CTD). A priority for the latter is to be capable of using existing sensor technologies that may not be miniaturized nor optimized for low-power operations, for example, relatively bulkier commercially available sensors unmodified [e.g., Wetlabs' water quality monitor (WQM); SubChem's autonomous profiling nutrient analyzer (APNA); Wetlabs' absorption and attenuation spectra (ac-s) optical package]; this is to enable the use of the wide range of sensors for which miniaturized and low-power versions may be unlikely to ever be developed, thus enabling a truly multidisciplinary range of sampling. (It would be feasible and relatively straightforward to install a pumped flow-through system for continuous sampling of surface water properties at any time the boat is underway; integrating this into the design was not a priority mainly because of the challenge biofouling presents for sensors exposed continuously during weeks-long deployments, which though still challenging is lessened for sensors only in contact with seawater during winched casts.) Operationally, COLREGs-based CA using onboard vessel detection and tracking sensors is a necessity, and vandal deterrence must be maximized. Finally, a design goal is to keep the cost for manufacturing and to use the final product within range of typical oceanographic research budgets.

The design process relied on SeaRobotics Corporation (Stuart, Florida) for its experience in the design and manufacture of MASCs. Its standard MASC product line at the time was mainly for protected waters, such as harbors, and short-duration deployments of up to a day, operated in remote control mode (i.e., not using onboard autonomy software). However, features of its vessels were considered amenable to relatively straightforward customization that could reach the design goals.

The energy budget is a core challenge, so preliminary estimates were assembled (Table 1) in order to assess feasibility and guide the design. Required power can be divided among three main components, in order of decreasing magnitude: propulsion, scientific sampling, and collective "house" demands (all other devices, including command/control, navigation, and datalogging electronics, communications to/from shore, lighting, AIS, GPS attitude sensor, etc.). For the feasibility estimates, the vessel is presumed to travel at $2.5 \mathrm{~m} \mathrm{~s}^{-1}$ between stations, run its ADCP continuously, and spend 10 min station keeping at each station (stopping only in one direction along the transect; see Fig. 1b) when the winch and winched sensor operate. Propulsion power estimates were 1500 and $300 \mathrm{~W}$, when in transit at $2.5 \mathrm{~m} \mathrm{~s}^{-1}$ and station keeping, and were recognized as uncertain but based on speed-power curves for suitably efficient vessels such as a catamaran with electric thrusters, in anticipation that SCOAP would take this form. The scientific sampling, and house, power demands in Table 1 are also rough, representative estimates based on commonly available sensors not optimized for low-power operations, and on initial designs of the anticipated winched profiling system, which will incorporate an altimeter on the lowered package for seafloor detection/avoidance. The total estimated need is $919 \mathrm{kWh}$, so the conclusion is that the required energy reserves are about $1000 \mathrm{kWh}$. Because propulsion is $90 \%$ of the total, this result will mainly be sensitive to the speed-power curve of the vessel, so hydrodynamic efficiency of the hull is a key priority. 
TABLE 1. Estimated energy budget during 30-day $(720 \mathrm{~h})$ deployment performing repeat-transect sampling on an 18 -km transect with 10 stations $2 \mathrm{~km}$ apart, with the ADCP operating continuously.

\begin{tabular}{|c|c|c|c|c|c|}
\hline & & Power (W) & Duration (h) & Requi & \\
\hline & In transit (at $2.5 \mathrm{~m} \mathrm{~s}^{-1}$ ) & 1500 & 508 & 762 & \\
\hline \multirow[t]{3}{*}{ Propulsion } & $\begin{array}{l}\text { Station keeping (10 min } \\
\text { per station) }\end{array}$ & 300 & 212 & 64 & \\
\hline & & & & Subtotal & 826 \\
\hline & $\begin{array}{l}\text { ADCP system (includes } \\
\text { datalogger, satellite } \\
\text { compass) }\end{array}$ & 10 & 720 & 7 & \\
\hline \multirow[t]{3}{*}{ Scientific sampling } & Winch & 150 & 212 & 32 & \\
\hline & Winched sensors & 150 & 212 & 32 & \\
\hline & & & & Subtotal & 71 \\
\hline \multirow[t]{2}{*}{ House } & & 30 & 720 & Subtotal & 22 \\
\hline & & & & Total & 919 \\
\hline
\end{tabular}

For design purposes with respect to seaworthiness, it was helpful to identify a concrete target location for demonstration operations. The $\sim 20-50$-m-deep waters of southeastern Rhode Island Sound (RIS) were selected (Fig. 2). RIS is a coastal sea facing the southern New England shelf off eastern North America, with partial exposure to open mid-Atlantic waters. Tidal currents range from about 10 to $40 \mathrm{~cm} \mathrm{~s}^{-1}$, weather-band currents are typically in the same range, residual currents are about $5-20 \mathrm{~cm} \mathrm{~s}^{-1}$, and wave conditions include significant wave heights typically about $1-3 \mathrm{~m}$ with infrequent maxima of about $5 \mathrm{~m}$ (Codiga and Ullman 2010; Ullman and Codiga 2010). Vessel traffic in the area, based on archived AIS data, is modest (Filimon 2013).

The target for vessel seaworthiness was to operate in sea states having significant wave heights in the ranges of $0-1.25 / 1.25-2.5 / 2.5-4.0 \mathrm{~m}$ during $60 \% / 30 \% / 10 \%$ of the deployment duration, respectively, based mainly on wave characteristics in RIS (Ullman and Codiga 2010). Goals for oceanographic data gathering capacity in these three categories of sea state were full capability (winch casts at all stations), reduced capability (winch casts at a subset of stations, operationally defined by pitch/roll conditions in which the winch system can operate), and nonoperational (the vessel could depart the site, as appropriate, until such high sea states subsided). This established the need for vessel stability, because increased vessel motion will degrade ADCP data quality and exacerbate challenges to winch operations. To the extent sampling capability is reduced during rougher sea states, estimates of transport will be biased toward calmer conditions.

Finally, key requirements are associated with the goal of unattended operations. The vessel must have lights and markings that are in keeping with CG requirements for unmanned vessels, on which guidance is available although they are currently not finalized. It also must incorporate an autonomous navigation capability that includes COLREGs-based collision avoidance, using onboard sensors to detect other vessels. Furthermore, for operational safety and to protect gathered data, all available measures must be taken to minimize the risk of vandalism.

\section{b. Design outcome}

The outcome of the SCOAP design process is a large (11-m length, 5-m beam) catamaran (Fig. 3) with electric thrusters, a large rechargeable battery bank with a diesel generator, and large-capacity fuel tanks (http:// www.po.gso.uri.edu/ codiga/scoap/SCOAP.htm). It is a custom vessel designed and manufactured by SeaRobotics with guidance and augmentations by the University of

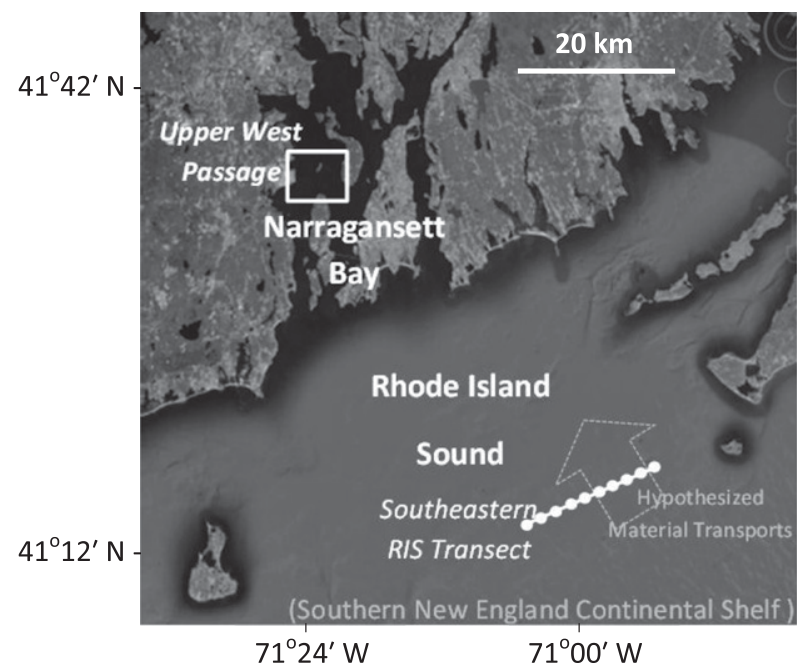

FIG. 2. Map showing southeastern Rhode Island Sound (RIS) transect (bottom right; targeted for future repeat-transect sampling, see Fig. 1b, during SCOAP open coastal demonstration deployment), to illustrate sampling goals. The initial test deployment reported on here was in the Upper West Passage of Narragansett Bay (box at top left, see Fig. 7). 

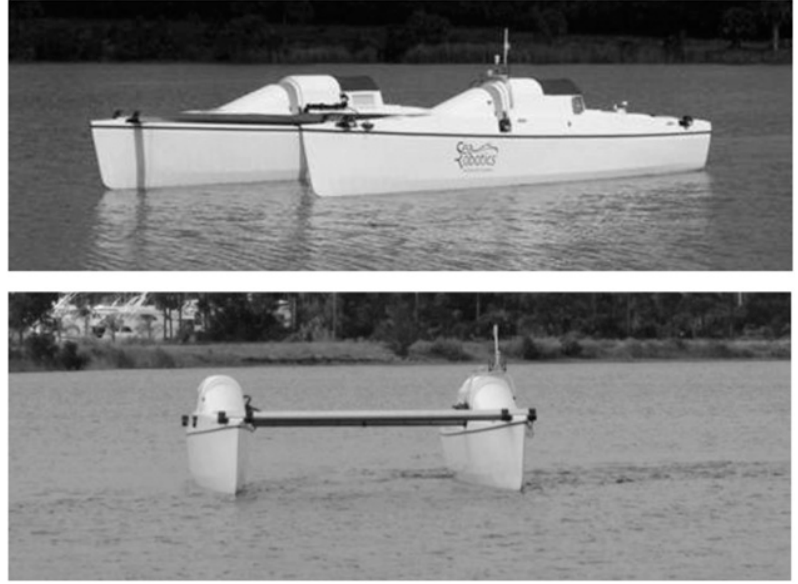

FIG. 3. Large catamaran MASC "SCOAP" ( 11-m length, $\sim 5$-m beam) in test trials on pond at SeaRobotics facility (Stuart, FL). (Photos: Jim Fontaine.)

Rhode Island. Most components are from the 4-m-long SeaRobotics USV-2600 product, but they were installed within larger hulls, provided with larger thrusters, and equipped with additional sensors. The large size of SCOAP is motivated by the requirements for seaworthiness, stability to facilitate collecting high-quality ADCP data and winch operations, and high capacity for energy reserves.

The hulls are a narrow design optimized for hydrodynamic efficiency (Fig. 4) to help facilitate adequately long endurance by reducing fuel consumption. Top speed in initial tests on a pond was more than $4 \mathrm{~m} \mathrm{~s}^{-1}$. To minimize mechanical complexity, the thrusters $(48-\mathrm{V}$ brushless, direct-current, geared propulsion motors with a highefficiency propeller design) are stationary, and steering is achieved by differential thrust. Guards are in place surrounding the propellers, in order to minimize risk of impact from rigid floating debris, and entanglement with seaweed, which is recognized as a potential limitation to unattended deployment duration.

The main battery bank consists of four advanced glass mat $12-\mathrm{V}$ cells, maintained by the generator (a $5.5-\mathrm{kW}$ marine diesel with integrated power management system), and two large fuel tanks with a maximum combined capacity of 380 gal. One tank is in each hull and a pump equilibrates their levels as fuel is drawn out of one, to maintain proper vessel ballast. Solar power generation was considered, and may be included as an auxiliary source in the future; it was however determined insufficient, as a sole power-generation source, to satisfy the needed long durations and reliability for on-demand propulsion to safely execute COLREGs-based CA.

The navigation/control system includes two Linuxbased CPUs. One CPU ("primary stack") executes simple
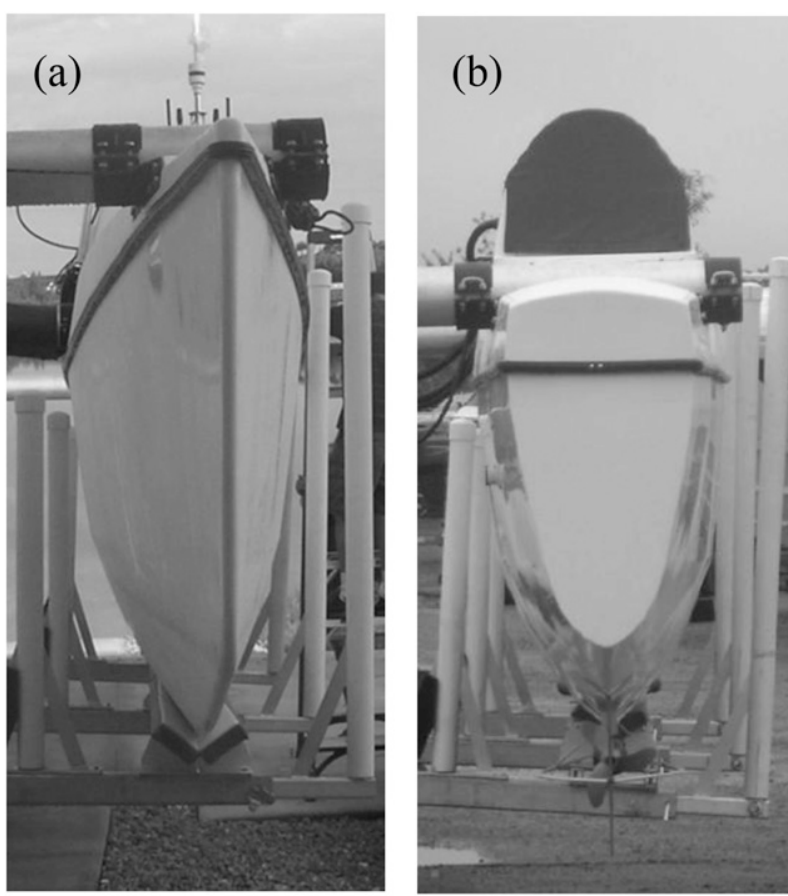

(c)

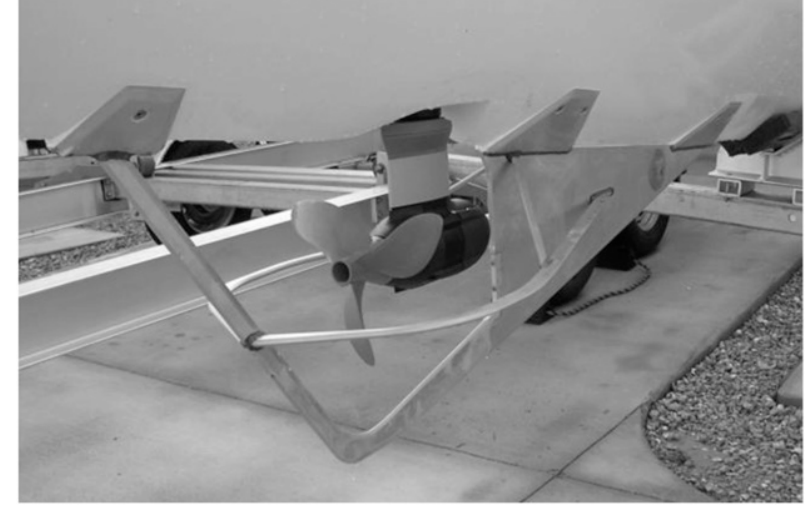

FIG. 4. SCOAP: (a) profile view of hull, port bow. (b) Profile view of hull, starboard stern; fixed propeller visible. (c) Propeller guard, perspective view (starboard). (Photos: Jim Fontaine.)

predefined missions with native SeaRobotics software. Another "backseat driver" CPU ("secondary stack") can host a third-party autonomy system for more sophisticated missions, for example, CA based on real-time sensor (e.g., AIS) detection of other vessels. The MOOS-IvP software suite (Benjamin et al. 2009) has been implemented (not reported on here) on the secondary stack. There is also a third processor dedicated to oceanographic sensor control and data acquisition using a standard Windows operating system.

High-quality GPS, yaw rate, attitude, and depth sounding sensors are installed. To date, one oceanographic 

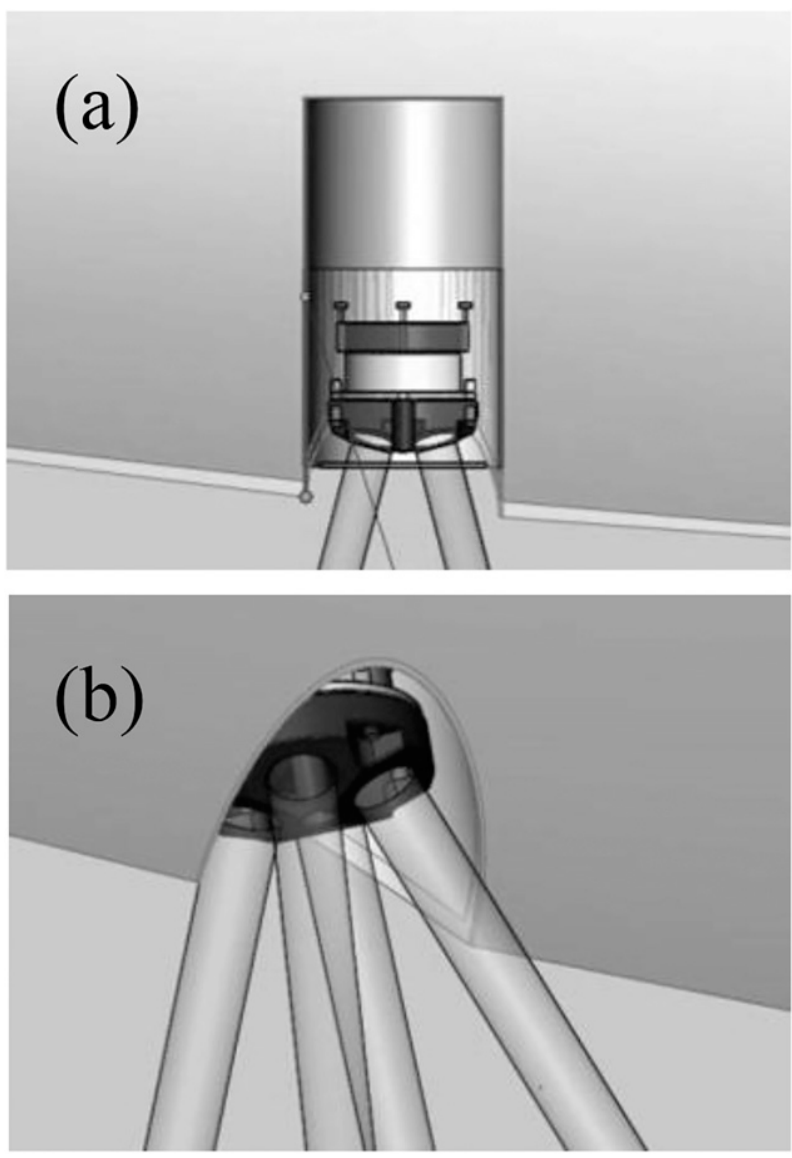

FIG. 5. Cutaway view of installation of ADCP in port hull viewed from between hulls. Acoustic beams shown as cylinders. (a) Perpendicular cross-section view. (b) Perspective view. (Renderings: Geoff Douglas, SeaRobotics.)

sensor has been installed, a hull-mounted $600-\mathrm{kHz}$ Teledyne RD Instruments ADCP (Fig. 5). In addition, a weather station (Airmar PB-150) is installed, for purposes of operationally monitoring wind conditions local to the boat; a future installation of a research-quality meteorological sensor suite is feasible and would be suitable for air-sea interaction studies. In anticipation that a winching system can later be installed, ample physical space is available, and the energy budget (Table 1 ) is intended to accommodate its power needs.

Line-of-sight radio frequency (RF) communications are used when the operator is physically on-site within a 1-2-km range of the catamaran, for example, during remote control operations. SCOAP is also equipped with satellite-based Iridium communication for operations in areas beyond cellular modem coverage, such as southeastern RIS; this low-bandwidth link is suitable when an unattended mission is being executed in the supervised autonomy mode, so status reports can automatically be sent to shore relatively infrequently (e.g., every $10 \mathrm{~min}$ ) (a)

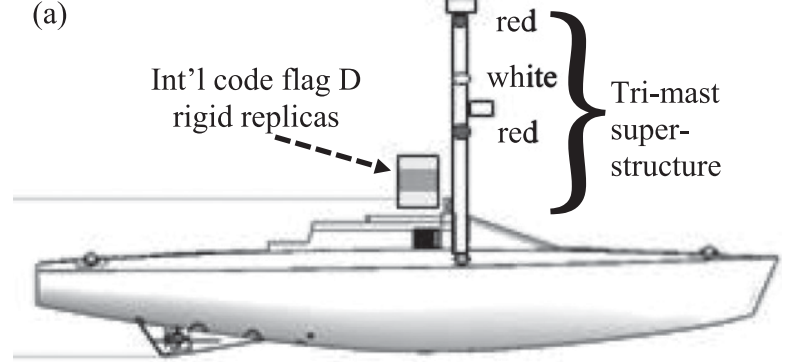

(b)

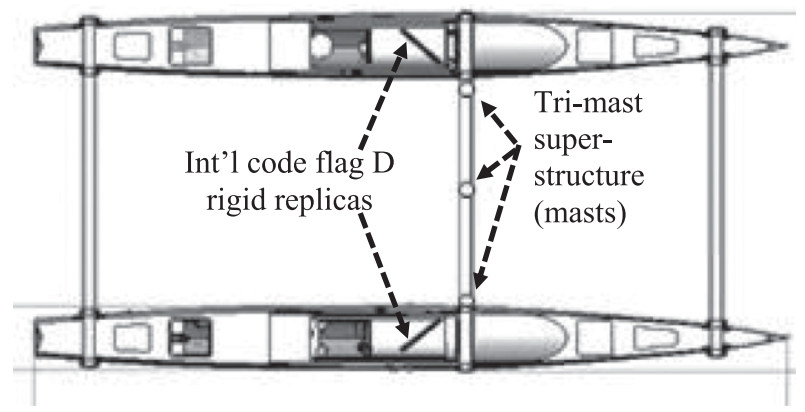

FIG. 6. Schematic showing (i) tri-mast superstructure design to support red over white over red all-round lighting at 4/3/2 $\mathrm{m}$ above gunwale (as well as various antennas), and (ii) placement of international code flag $\mathrm{D}$ rigid replicas, for all-round visibility. (a) View from starboard side. (b) Plan view.

while navigation decisions are made autonomously multiple times per second by the onboard software (in this case, MOOS-IvP Helm).

CG guidance for vessels operated without a person on board is being followed closely. The boat is equipped with AIS (class B). An active dual-band echo sounder is also being installed to help ensure detection of SCOAP by radar systems on other vessels. To convey "maneuvering with difficulty" status, a tri-mast structure will be equipped with red over white over red all-round lights at 4/3/2-m height off the gunwale, and international code flag D rigid replicas will be incorporated with a mesh design to reduce windage (Fig. 6). Onboard autonomy software for COLREGs-based CA using sensor input, currently in the testing stages, will be implemented.

Risk of vandalism to any unattended vessel is a serious concern; oceanographic buoys deployed near the targeted southeastern RIS transect in recent years have sustained gunshot damage. Antiballistic panels were therefore incorporated in SCOAP surrounding the control/navigation and data storage systems. To help deter vandals, the hulls will also be given prominent visible markings in large reflective lettering, indicating the MASC is monitored from shore 24/7, and warning against boarding or tampering with it.

Finally, the cost of this prototype unit to the National Science Foundation grant was held, through investment 


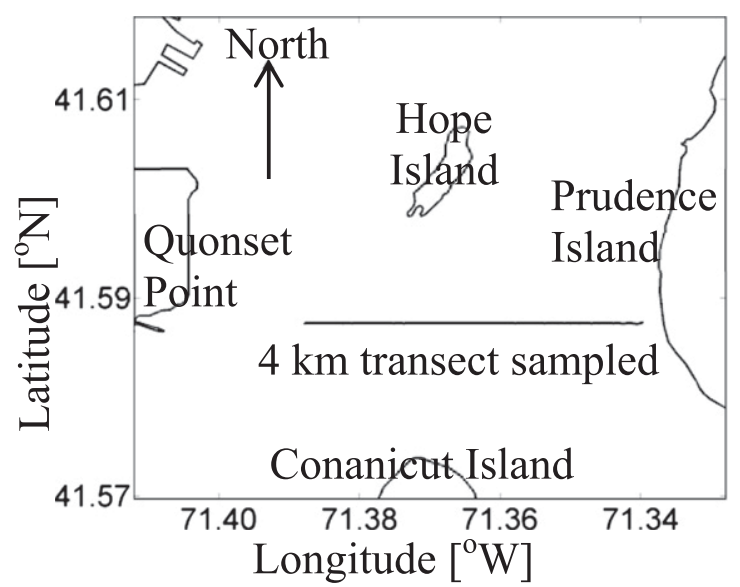

FIG. 7. Map of portion of Upper West Passage in Narragansett Bay (see box in Fig. 2), site of SCOAP test deployment reported on here. The east-west transect sampled is indicated using GPS fixes made by SCOAP during westward-traveled crossing 2, which form the east-west black line $4 \mathrm{~km}$ long, and are indicative that the path of the boat did not deviate from the designated transect by more than $1-2 \mathrm{~m}$.

in the project by SeaRobotics, to less than $\$ 200,000$ including the custom hull-retracting boat trailer. Future production in larger numbers could, without such manufacturer involvement, keep the cost to oceanographers at about the same level or less. Therefore, it is in range of oceanographic research project budgets.

\section{Initial SCOAP field deployment}

This initial fieldwork was in the relatively protected waters of Narragansett Bay (NB; described next); tests in open coastal conditions (e.g., RIS) are a later stage of the planned series of deployments. The focus for the deployment reported here was mainly on gaining confidence in propulsion, seaworthiness, endurance, and ADCP sampling capabilities. Accordingly, a small research vessel escorted SCOAP to and from the site and was present throughout the deployment; the native SeaRobotics mission control software was relied on (demonstration of third-party MOOS-IvP Helm autonomy software will be reported later); and the tri-mast, code flag D replicas, and vandal deterrence markings were not needed nor yet in place.

The deployment took place on 25 September 2013 in Upper West Passage (UWP) of NB (Fig. 7), in 5-15-mwater depths. Significant wave heights were approximately $0.25-1 \mathrm{~m}$ (judged visually, observations unavailable) and varied over the course of the day, as is typical for this area and time of year. Winds were also typical for September, at about $5-10 \mathrm{kt}$ with some stronger periods, including gusts to $15-20 \mathrm{kt}$. Tidal currents flow predominantly northward (southward) across the transect during flood (ebb), are dominated by the semidiurnal $M_{2}$ constituent (period $12.42 \mathrm{~h}$ ), and reach amplitudes of about $25 \mathrm{~cm} \mathrm{~s}^{-1}$ (e.g., Spaulding and Swanson 2008).

The oceanographic sampling aim for the deployment was to collect ADCP observations, repeatedly through most of a tidal cycle, of vertical profiles of horizontal velocities along a transect; the lateral and vertical structure of currents in this region is poorly known. The transect is $4 \mathrm{~km}$ long and was completed a total of 18 times (9 eastward and 9 westward crossings) over a period of about $9 \mathrm{~h}$ spanning both peak flood and peak ebb. The ADCP operated continuously, with 1-m bin size, and recorded a profile every ping (each $2 \mathrm{~s}$ ).

Remote control operations were only implemented during transit to and from the site; when on the transect, navigation was controlled by the SeaRobotics mission software on board the vessel, operating in waypoint mode. Waypoint mode implements an algorithm that attempts to maintain a constant thrust level, which was set to $60 \%$ of the maximum thrust available in this case, while progressing toward the target waypoint but also minimizing distance from the transect. If displaced laterally from the trackline, the algorithm will apply thrust to return toward the trackline, in addition to proceeding along the trackline, while maintaining the same constant thrust level and therefore achieving slower speed toward the waypoint.

Representative environmental conditions, vessel response, and generator cycling are seen in 1-s-averaged time series from the $\sim 36$-min duration of the westwardmoving crossing 2 of the 4-km transect (Fig. 8). Wind speed (observations from nearby Quonset Point, Fig. 7, by the National Oceanic and Atmospheric Administration) was moderate, in the range of about $1-5 \mathrm{~m} \mathrm{~s}^{-1}$ or 2-10kt (Fig. 8a). Pitch had a positive mean value with high-frequency variability peaking at about $\pm 1.5^{\circ}$ and lessening to a minimum of about $\pm 0.25^{\circ}$ during a representative $\sim 5$-min-interval midtransect; roll had a negative mean value with slightly higher variability of between about $\pm 2^{\circ}$ and $\pm 0.5^{\circ}$ (Fig. 8a).

Generator activity is revealed by main battery bank voltage (Fig. 8b): initially the generator happened to be running and charging the main batteries $\left(V_{\text {main }} \sim\right.$ $55-56 \mathrm{~V})$, and then about $3 \mathrm{~min}$ into the crossing the generator shut down and for $\sim 15 \mathrm{~min}$ the batteries sustained power $\left(V_{\text {main }} \sim 49.5 \mathrm{~V}\right.$ decreasing to $\sim 47.5 \mathrm{~V}$ ). At that point the generator started and the cycle repeated. Current $I_{\text {total }}$ drawn (Fig. 8b) from the main batteries (for all needs - propulsion, sensors, house — but dominated by propulsion) showed typical values in the range of 5-40 A and peaks of $70+\mathrm{A}$. The high-frequency variability, 


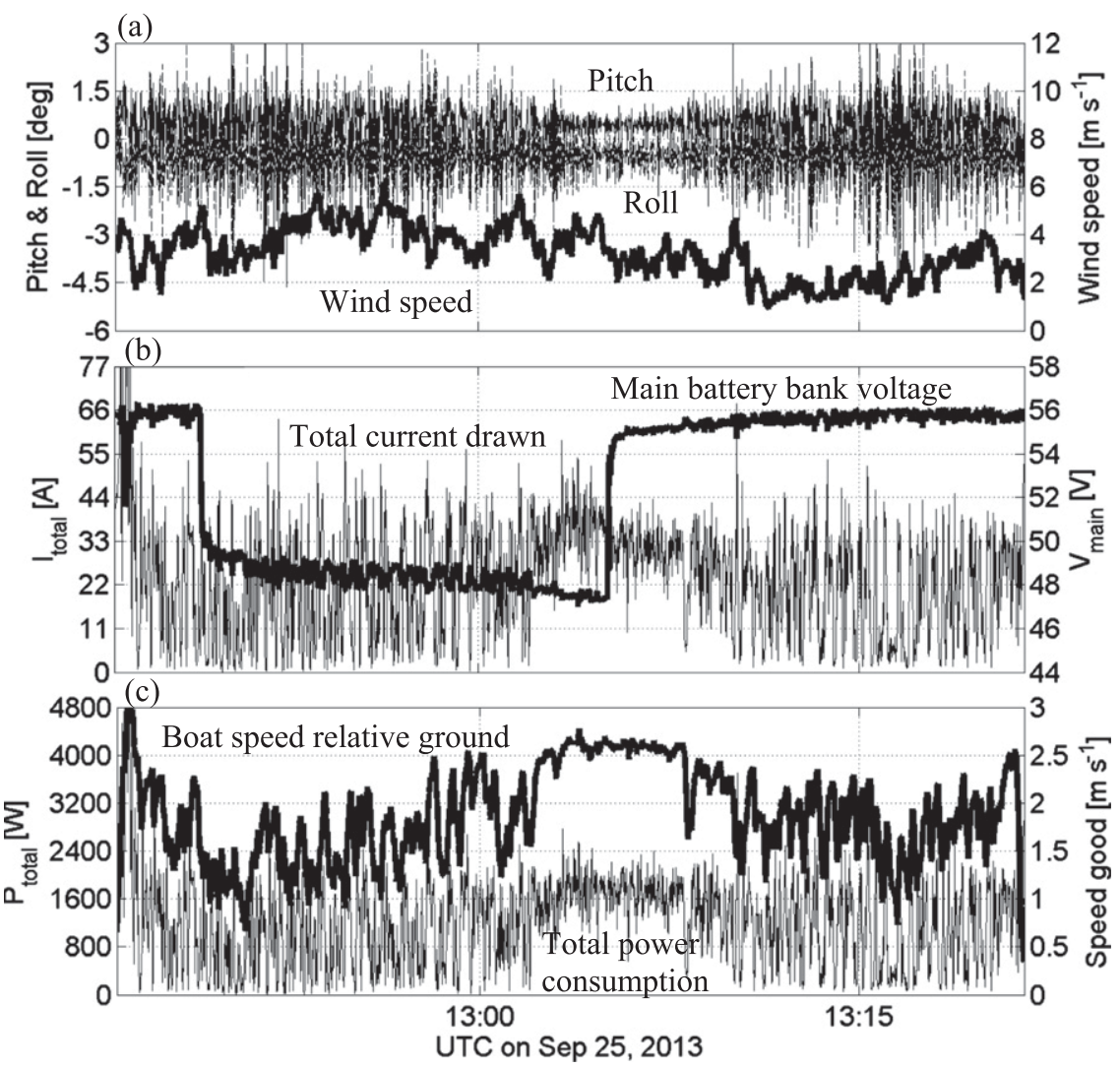

FIG. 8. Time series-measured parameters (1-s averaged) during the 36-min-duration westward crossing 2 of the 4-km transect (shown in Fig. 7). (a) Left axis: pitch and roll; right axis (bold): wind speed. (b) Left axis: total current drawn $I_{\text {total }}$ from main battery bank; right axis (bold): voltage $V_{\text {main }}$ of main battery bank. (c) Left axis: total power consumption rate $\left(P_{\text {total }}=\right.$ $I_{\text {total }} \times V_{\text {main }}$ ); right axis (bold): vessel speed relative to ground.

loosely parallel to that of pitch and roll, is associated with the waypoint-following algorithm, which applied thrust adjustments multiple times per second in order to maintain the vessel very close (1-2-m-distance max; typically $<1 \mathrm{~m})$ to the transect.

The boat speed (Fig. 8c) relative to the ground varied from about 0.75 to $2.75 \mathrm{~m} \mathrm{~s}^{-1}$ and also exhibited highfrequency variability in parallel with pitch and roll. During the midsegment interval with low pitch/roll, the $60 \%$ thrust level yielded a speed of about $2.5 \mathrm{~m} \mathrm{~s}^{-1}$, whereas the same thrust level generally yielded slower speed at other times. A local maximum in sustained total power consumption (computed as $I_{\text {total }} \times V_{\text {main }}$; Fig. 8c) was about 1500-2000 W during the midsegment interval, and it reached up to $4500 \mathrm{~W}$ for short periods at the start of the crossing.

Variations in conditions and performance during the $\sim 9 \mathrm{~h}$ of sampling are revealed by means and standard deviations computed using individual crossings (Fig. 9). Mean wind speeds (Fig. 9a) ranged from about 2 to $5 \mathrm{~m} \mathrm{~s}^{-1}$, with an eastward component for the first part of the day then a westward component. Thus, the boat faced headwinds (downward black arrows, Fig. 9b) during the initial westward crossings and then during eastward crossings for the remainder of the day. Winds also exhibited a sea-breeze pattern with downbay (southward) directed morning and midday winds and a transition to more landward (northward) winds in the late afternoon.

RMS pitch and roll (Fig. 9c) give an indication of wave conditions (for which no measurements were available). They generally rise and fall with each other, and in parallel with the wind speed. Peak and minimal significant wave heights of 1 and $0.25 \mathrm{~m}$ (gauged visually) corresponded to RMS pitch (roll) of about $1.5^{\circ}\left(0.5^{\circ}\right)$ and $0.25^{\circ}\left(0.1^{\circ}\right)$, respectively. These results permit a partial assessment of performance relative to the design goals for seaworthiness (prior section) and suggest they are unlikely not to be met.

Crossing-mean vessel speed ranged from about 1.75 to $2.75 \mathrm{~m} \mathrm{~s}^{-1}$ with 1 -s standard deviations from 0.25 to $0.5 \mathrm{~m} \mathrm{~s}^{-1}$ (Fig. 9d). The lowest speeds generally occurred when winds and pitch/roll were strongest (crossings 

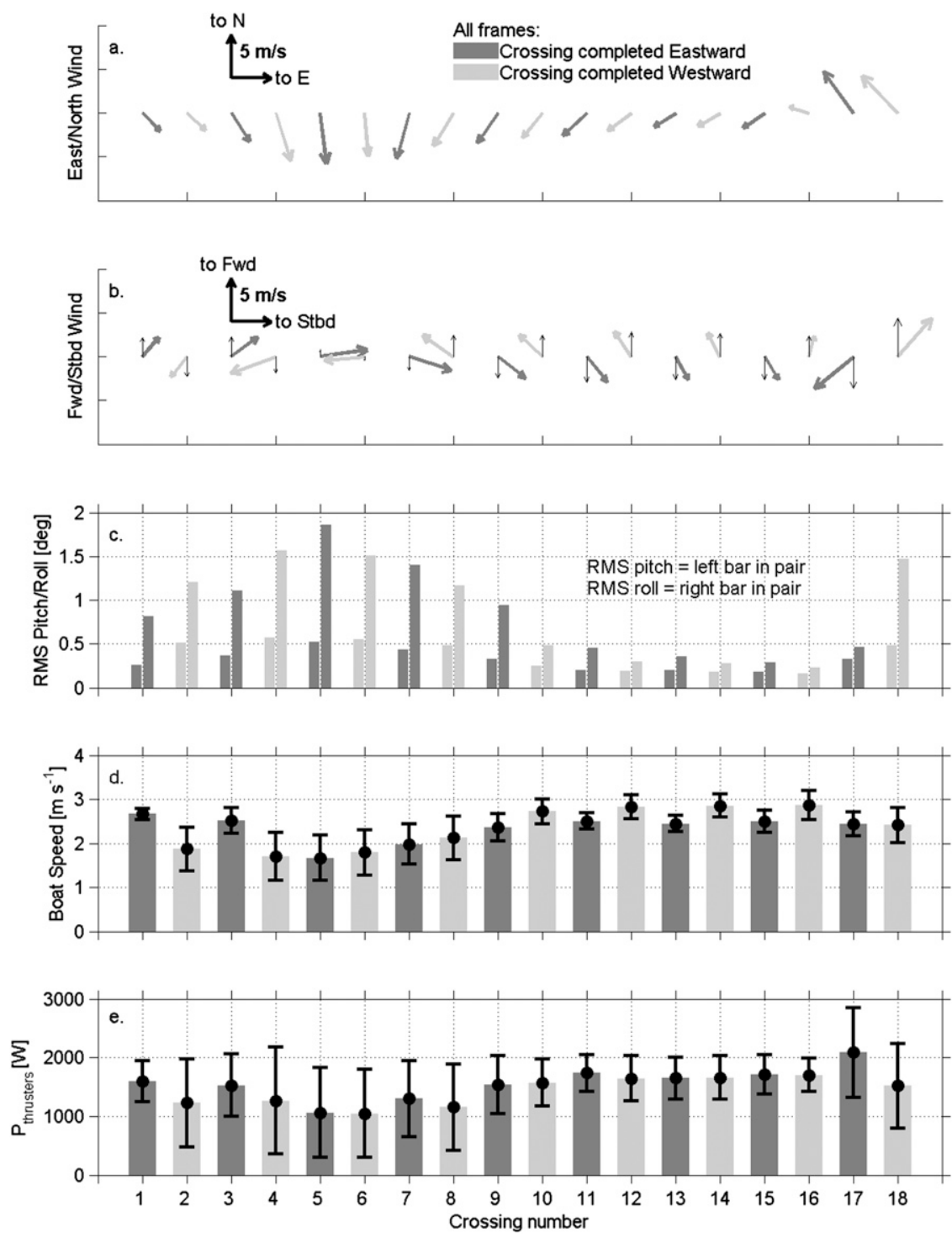

FIG. 9. Crossing-mean conditions and performance. In all frames, results from crossings completed eastward (westward) are shown in dark (light) gray. (a) Vector winds (gray) in standard eastward-northward coordinates. (b) Vector winds (gray) in coordinates based on the direction the crossing is completed: forward and starboard. Also shown is the along-crossing wind (black; upward is tailwind; downward is headwind). (c) RMS pitch (left bar in pair) and RMS roll (right bars). (d) Crossing-mean vessel speed, with standard deviation of 1-s values. (e) Power drawn by thrusters, as shown in (d).

4-7); periods when speed was lower appear to correspond with higher across-transect winds, consistent with the behavior of the track-following algorithm as noted above. In addition, the difference in speed between immediately subsequent crossing pairs was consistent with headwinds being the most important factor (e.g., upwind crossings $2,4,9,11,13,15$, and 17 slower than downwind crossings $1,3,10,12,14,16$, and 18 , respectively), since differences in pitch/roll conditions of consecutive crossings were not as pronounced.
Crossing-mean power applied to the thrusters (Fig. 9e) was in the range of $1100-2100 \mathrm{~W}$, with standard deviations of about 300-900 W. Very generally, the power drawn was higher (lower) when the vessel speed was higher (lower). For example, among crossings $1-4$, the lower-speed crossings during headwinds used less power and vice versa. However, the relationship between power drawn and vessel speed exhibited variability. During crossings $10-15$, a difference in power during slower upwind and faster downwind crossings was not 


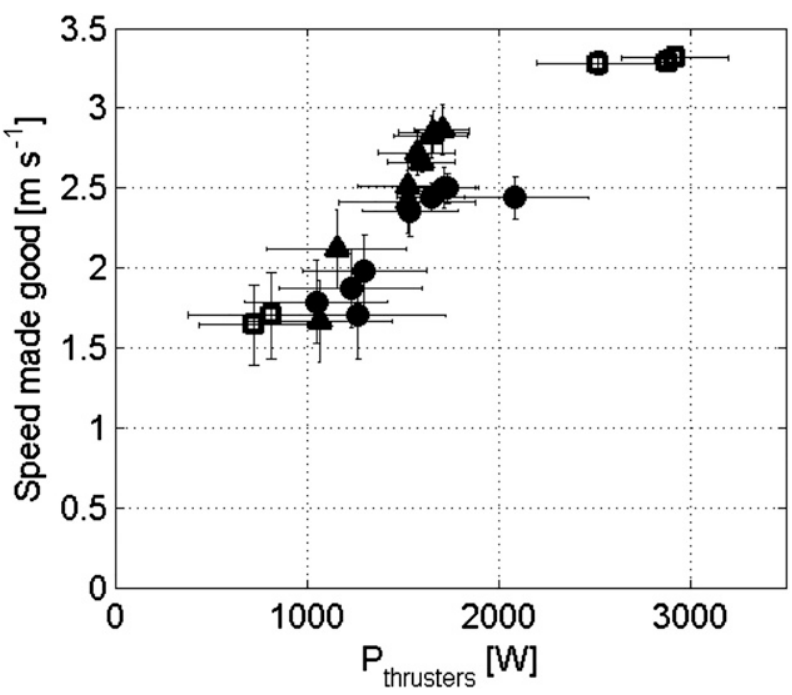

FIG. 10. Speed-power curve. Solid symbols are crossing means (circles, upwind crossings; triangles, downwind crossings) during waypoint mode with $60 \%$ thrust and track-following algorithm; variations are due to changes in wind/wave/current conditions. Open squares at higher and lower power ranges are from shorterduration intervals (2.5-13.5 min) of remote control operations (not waypoint mode) using higher and lower percent thrust. Total error bar lengths depict standard deviations.

apparent. In some cases, more power was drawn during slower crossings (11 and 17 compared to faster 10 and 16 , respectively). This range of variations is considered to be a function of the track-following navigation algorithm. It sought to maintain thrust at $60 \%$ of maximum, but also steered laterally back toward the desired track, instead of making progress along the track, when the boat was displaced perpendicularly from the track. Thus, power used in order to make a given speed along the track is expected to vary under wind, wave, and current conditions with different dominant directionalities.

A speed-power curve for this deployment has been constructed (Fig. 10). When operated in waypoint mode with its track-following algorithm, at $60 \%$ thrust, in this specific set of wind/wave conditions, the crossing-mean speed is in the range of $1.6-2.8 \mathrm{~m} \mathrm{~s}^{-1}$ for thruster power consumption of about $1000-2000 \mathrm{~W}$. Thus, the value of $1500 \mathrm{~W}$ for power required for a speed of $2.5 \mathrm{~m} \mathrm{~s}^{-1}$ during feasibility evaluation (Table 1) has been confirmed as reasonably appropriate for these conditions. When operated by remote control (no track following) at a higher percent thrust, in response to $3000-\mathrm{W}$ power a peak speed of $3.3 \mathrm{~m} \mathrm{~s}^{-1}$ was reached; this point on the curve makes apparent the expected nonlinearity in which diminishing speed increases occur, for given increases in power applied, at increasing speeds.

Cycling of the generator on and off to recharge the main battery bank led to a total of 4.2 gal of diesel fuel consumed during the 10 -h deployment. Scaled up to a 1-month deployment, the requirement would be 302 gal. Because the fuel tanks have a 380-gal maximum capacity, a 1-month unattended deployment in these conditions is certainly feasible in terms of onboard energy reserves. In more challenging winds, waves, and currents, fuel efficiency will go down. However, fuel efficiency is also expected to go up substantially on use of a different track-following algorithm (e.g., the MOOS-IvP waypoint behavior; Benjamin et al. 2009), and/or use of different parameters governing the trackfollowing behavior, to permit larger deviations from the desired track and thus use less fuel moving perpendicularly toward the track when displaced off it. Larger perpendicular deviations (e.g., 5-10 $\mathrm{m}$ or more) will not degrade the scientific value of the sampling, as they are small relative to the 4-km transect length. In the event fuel consumption is substantially higher than estimated here-either due to decreased propulsion efficiency in more challenging wave, wind, or current conditions, or perhaps due to increased consumption by markedly expanded oceanographic sensor power demand-the duration of the deployment could be reduced to three or two weeks and still generate valuable and unique observations.

The ADCP performed well, collecting oceanographically useful measurements of water velocity profiles (subset of data, Fig. 11). The catamaran is sufficiently stable, the ADCP beams are not obstructed, vibrational or electronic noise issues are not problematic, and no bubble interference is apparent. Based on experience with ADCP water velocity measurements from research vessels in similar conditions, the observations collected are of comparable quality. Higher-quality heading data, as will be gathered by a Furuno SC-50 satellite compass being installed on the tri-mast for future deployments, will further improve ADCP data quality.

\section{Discussion}

Motivation for development of SCOAP was a comparison of currently available observational platforms, in the context of sampling and operational needs, to measure residual transport of multidisciplinary waterborne materials through a section in coastal/estuarine waters (section 2b). This led to the conclusion that a large catamaran MASC could have important strengths. Traditional platforms are inadequate. Use of moorings would require large numbers, leading to unacceptable costs, and regardless is operationally infeasible in waterways with heavy vessel traffic. Maintaining a research vessel at a given site continuously for sufficiently long durations is also cost prohibitive. 

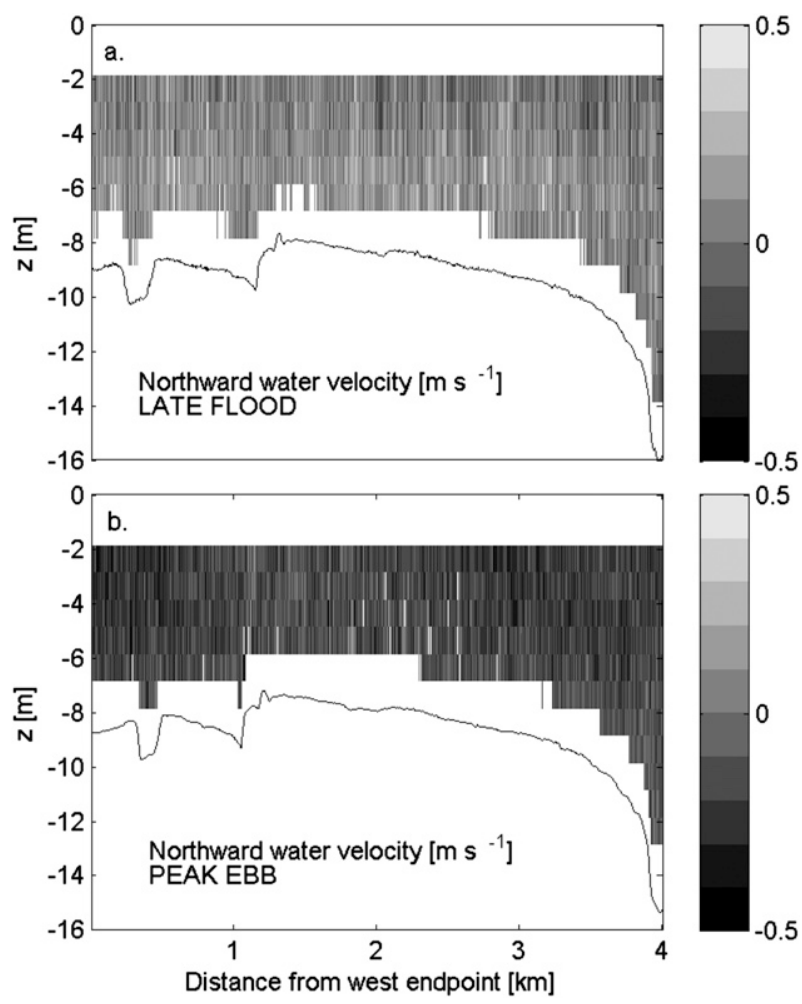

FIG. 11. Northward water velocity (computed using bottomtrack reference) measured by the ADCP during (a) late flood (eastward crossing 5) and (b) peak ebb (eastward crossing 15). Black lines indicate seafloor measured by bottom tracking. Each crossing lasted approximately $25-30 \mathrm{~min}$.

The main types of available mobile platforms include autonomous underwater vehicles (AUVs; e.g., Griffiths 2002), subsurface gliders such as Slocum, SeaGlider, and Spray (e.g., Rudnick et al. 2004), and smaller MASCs such as the wave-powered Wave Glider (Manley and Willcox 2010). Each is proven, particularly in deeper waters, but each faces serious challenges in meeting the sampling and operational goals described above for shallow-water conditions where currents are strong and vessel traffic is heavy. The speed they can sustain for long periods is generally at most about half as fast as the $2.5 \mathrm{~m} \mathrm{~s}^{-1}$ target argued necessary (section $2 \mathrm{~b}$ ), and typically less. Thus, at least two such units would be needed, to achieve material transport sampling equivalent to that of a single large catamaran MASC such as SCOAP, driving costs up. Their relatively smaller sizes also generally limit the energy resources they can host, leading to the constraint that only scientific sensors that are optimized for low power can be used, thus ruling out a range of important multidisciplinary sensors. These factors collectively lead to the view that large catamaran MASCs could play an important role in fully multidisciplinary observing strategies. In particular they could

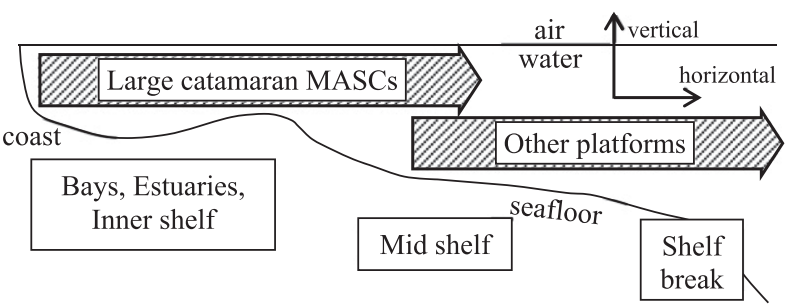

FIG. 12. Generalized schematic showing regions (inshore coastal and estuarine systems characterized by shallow and variable bathymetries, strong currents, and heavy vessel traffic) where large catamaran MASCs such as SCOAP could be more suited for operational reliability and cost effectiveness as multidisciplinary oceanographic sampling platforms, as compared to other mobile platform technologies including AUVs, subsurface gliders, and smaller wave-driven MASCs such as Wave Gliders.

fill gaps in observing systems based on other mobile platforms (Fig. 12) - for example, being able to sample farther inshore, more frequently, and with a broader range of sensors as compared to an underwater glider network currently being planned (Baltes et al. 2014). The size and stability of a large catamaran MASC offers potential for higher-quality meteorological and vesselmounted ADCP sampling. Furthermore, a large catamaran MASC is naturally suited for deployments in coordination with other platforms, where it can serve as a communications node, for example, by acoustic links to underwater platforms.

Historically, there have been two main classes of MASC (e.g., Manley 2008). The first includes smaller size vessels for short-term deployments, generally in protected waters such as harbors, lakes, and rivers for applications such as hull inspections and short-term surveys. Examples include the Q-Boat from Oceanscience, surface craft for oceanographic and undersea testing (SCOUT) from Maribotics, and the USV-2600 from SeaRobotics (e.g., Brown et al. 2011). The second group is larger and has very high-speed and relatively expensive boats lacking human operators on board, but with teams of people operating them remotely, mostly in military USV applications. Examples include Owl, Stingray, and Sea Fox (e.g., NRC 2005). Neither class addresses the need for which SCOAP is specifically designed: operations in conditions of open coastal waters and large estuaries, for long durations unattended, with collision avoidance capabilities, at a cost suitable for oceanographic projects.

Earlier custom research MASCs with somewhat similar designs and goals to that of SCOAP include Delfim (e.g., Pascoal et al. 2006), the Sea Surface Autonomous Modular Unit (SESAMO; Caccia et al. 2005), Roaz II (Ferreira et al. 2012), and the Ocean Atmosphere Sensor Integration System (OASIS; Higinbotham et al. 
2008). More recently there has been a major expansion in development of novel surface craft potentially suitable to pursue the aims SCOAP addresses (see reviews by Yang et al. 2011 and MTR 2013). Newer lightweight catamarans include the Sonobot from Evologics (http:// www.evologics.de) and H-1750 from Deep Ocean (http://www.deepocean.com) though neither is suitably seaworthy for wave conditions of open coastal waters. At least three fixed-wing sailcraft are in advanced development stages (Harbor Wing Technologies, http://www.harborwingtech.com; SailDrone, http://www. saildrone.com; Datamaran, http://www.automarinesys. com) and show promise. However, they are constructed from costly specialized materials, include complex customized software engineering for mechanical navigation control, and seem unlikely to be well suited for performing CA maneuvers given that their propulsion is solely or primarily wind based. Finally, more complex custom-engineered vessels such as the C-Enduro or C-Workman (http://www.asvglobal.com), WAM-V (http://www.wam-v.com), swath designs (Brizzolara et al. 2012), and semisubmersibles generally remain out of reach for oceanographic research/monitoring project budgets. The MASCs discussed here do not represent an exhaustive list [Motwani (2012) gives a more comprehensive review] but nonetheless serve to demonstrate that a large catamaran MASC such as SCOAP has an advantageous combination of strong capabilities for sampling and operational goals in coastal/estuarine settings, with a relatively simple and cost-effective configuration suitable for oceanographic research. Distinguishing aspects of the SCOAP design are its combination of relatively large size, emphasis on longduration unattended deployments, integration of a winched profiler handling multidisciplinary sensors not optimized for low power, intended reliance on onboard autonomy software for COLREGs-based CA, and relatively low cost.

Algorithms for COLREGs-based CA in MOOS-IvP are in late testing stages (M. Benjamin 2014, personal communication) and will be implemented on SCOAP. Onboard detection of other vessels will be by AIS initially. However, vessels not equipped with AIS, such as smaller fishing and recreational boats, present a major challenge. Adding a radar system (see, e.g., Almeida et al. 2009) is motivated, for which an inexpensive commercially available low-power broadband unit (e.g., Navico as discussed by Dabrowski et al. 2011) well suited to detect vessels at short range is expected to be a good solution. The large size of SCOAP is anticipated to be a strength, in addition to its other benefits discussed above, with regard to stability for successful operation of the radar system for real-time target identification and tracking, to be input to the CA software system. Other possibilities for detection of non-AIS vessels include lidar (e.g., Campbell et al. 2014) and visible-wavelength image analysis systems (e.g., as offered by Automatic Sea Vision, http://www.asv.fr).

\section{Concluding remarks}

Knowledge of residual transports of water and waterborne materials is crucial to understanding nearly all oceanographic processes in coastal and estuarine ecosystems. Sampling issues associated with measuring such transports through a transect (Fig. 1) have been examined in detail. Water column profiles of both Earthreferenced horizontal velocities and concentrations of the transported property of interest are required; the coverage and resolution, both spatially and temporally, are demanding. This motivated development of SCOAP (Figs. 3-6), a large catamaran MASC designed to be a stable platform for monthlong, spatially explicit, repeat-transect, unattended multidisciplinary sampling, including water column profiles collected by a winch using sensors that need not be optimized for low-power operations, in sea states up to those of open coastal conditions. An initial SCOAP test deployment in estuarine waters of Narragansett Bay (Fig. 2) with moderate wind and wave exposure (Fig. 7) has been reported (Figs. 8-10). Aspects of its propulsion, seaworthiness, endurance, and ADCP sampling capabilities (Fig. 11) were assessed and shown to be meeting the design goals. Next steps include installation of lighting and markings based on CG guidance for unmanned vessels (Fig. 6), implementation of autonomy software for COLREGsbased CA, and a further series of incremental field tests leading up to the culminating goal of a monthlong unattended ADCP survey in exposed open coastal waters of RIS, in preparation for the addition of a winched profiling system. In many systems-particularly those with relatively shallow and variable bathymetry, energetic tidal currents, and high vessel traffic - the sampling needs SCOAP is designed for cannot be met particularly well by available observational platforms, for operational reasons and/or budgetary constraints of oceanographic research projects. Thus, there is potential that large catamarans such as SCOAP could help fill a need in ocean observing systems (Fig. 12).

Acknowledgments. Jim Fontaine (Exeter Science Services) delivered expert custom engineering and technical design and execution throughout the project. At URI Mike Filimon used archived AIS data for RIS deployment planning, and simulated CA in MOOS-IvP; Amit Nehra was skillful with remote control, software 
configurations, and videography; Steve Granger is thanked for providing safe and reliable escort boat services; Dave Ullman generously lent the ADCP with bottom track installed; and Dennis Nixon provided expertise on various legal and practical matters. Don Darling, Geoff Douglas, Hal Dewar, and Rich Musco from SeaRobotics have been responsive and supportive since the earliest design phase. Guidance from Ed Leblanc, of CG Sector Southern New England, was crucial. Funding was provided by NSF Ocean Technology and Interdisciplinary Coordination, Award 1131390, Program Manager Kandace Binkley.

\section{REFERENCES}

Almeida, C., T. Franco, H. Ferreira, A. Martins, R. Santos, J. M. Almeida, J. Carvalho, and E. Silva, 2009: Radar based collision detection developments on USV ROAZ II. OCEANS 2009Europe, IEEE, 1-6, doi:10.1109/OCEANSE.2009.5278238.

Arroyo, J., 2011: The Automatic Identification System: Then, now and in the future. Proc. Mar. Saf. Secur. Counc., 68, 51-57.

Baltes, B., and Coauthors, 2014: Toward a U.S. IOOS underwater glider network plan: Part of a comprehensive subsurface observing system. NOAA Integrated Ocean Observing System White Paper, 54 pp.

Benjamin, M. R., J. J. Leonard, J. A. Curcio, and P. M. Newman, 2006: A method for protocol-based collision avoidance between autonomous marine surface craft. J. Field Rob., 23, 333 346, doi:10.1002/rob.20121.

_, P. Newman, H. Schmidt, and J. J. Leonard, 2009: An overview of MOOS-IvP and a users guide to the IvP Helm autonomy software. MIT Computer Science and Artificial Intelligence Laboratory Tech. Rep. MIT-CSAIL-TR-2010-041, 255 pp.

Brizzolara, S., T. Curtin, M. Bovio, and G. Vernengo, 2012: Concept design and hydrodynamic optimization of an innovative SWATH USV by CFD methods. Ocean Dyn., 62, 227-237, doi:10.1007/s10236-011-0471-y.

Brown, J., C. Tuggle, J. MacMahan, and A. Reniers, 2011: The use of autonomous vehicles for spatially measuring mean velocity profiles in rivers and estuaries. Intell. Serv. Rob., 4, 233-244, doi:10.1007/s11370-011-0095-6.

Caccia, M., R. Bono, G. Bruzzione, G. Bruzzione, E. Spirandelli, G. Veruggio, A. M. Stortini, and G. Capodaglio, 2005: Sampling sea surfaces with SESAMO: An autonomous craft for the study of sea-air interactions. IEEE Robot. Autom. Mag., 12, 95-105, doi:10.1109/MRA.2005.1511873.

Campbell, S., M. Abu-Tair, and W. Naeem, 2014: An automatic COLREGs-compliant obstacle avoidance system for an unmanned surface vehicle. Proc. Inst. Mech. Eng., 228M, 108121 doi:10.1177/1475090213498229.

Codiga, D. L., 2011: Unified tidal analysis and prediction using the "UTide" Matlab functions. Graduate School of Oceanography, University of Rhode Island, Tech. Rep. 2011-01, 59 pp.

- , and D. A. Aurin, 2007: Residual circulation in eastern Long Island Sound: Observed transverse-vertical structure and exchange transport. Cont. Shelf Res., 27, 103-116, doi:10.1016/ j.csr.2006.09.001.

, and D. S. Ullman, 2010: Characterizing the physical oceanography of coastal waters off Rhode Island, Part 1: Literature review, available observations, and a representative model simulation. Appendix to Rhode Island Ocean Special Area Management Plan 2010, University of Rhode Island, 169 pp.

Dabrowski, A., S. Busch, and R. Stelzer, 2011: A digital interface for imagery and control of a Navico/Lowrance broadband radar. Robotic Sailing: Proceedings of the 4th International Robotic Sailing Conference, A. Schlaefer and O. Blaurock, Eds., Springer, 169-181, doi:10.1007/978-3-642-22836-0_12.

Ferreira, H., C. Almeida, A. Martins, J. Almeida, A. Diaz, G. Silva, and E. Silva, 2012: Environmental modeling with precision navigation using ROAZ autonomous surface vehicle. IROS12: Workshop on Robotics for Environmental Monitoring, Vilamoura, Portugal, $6 \mathrm{pp}$. [Available online at http:// wrem2012.isr.uc.pt/Papers/Ferreira_WREM2012.pdf.]

Filimon, M. A., 2013: Site planning and on-board collision avoidance software to optimize autonomous surface craft surveys M.S. thesis, Dept. of Ocean Engineering, University of Rhode Island, $62 \mathrm{pp}$.

Griffiths, G. E., Ed., 2002: Technology and Applications of Autonomous Underwater Vehicles. Ocean Science and Technology Series, Book 2, CRC Press, 368 pp.

Higinbotham, J. R., J. R. Moisan, C. Schirtzinger, M. Linkswiler, J. Yungel, and P. Orton, 2008: Update on the development and testing of a new long duration solar powered autonomous surface vehicle. OCEANS 2008, IEEE, 1-10, doi:10.1109/ OCEANS.2008.5152048.

Kuwata, Y., M. T. Wolf, D. Zarzhitsky, and T. L. Huntsberger, 2011: Safe maritime navigation with COLREGS using velocity obstacles. 2011 IEEE/RSJ International Conference on Intelligent Robots and Systems, N. M. Amato, Ed., IEEE, 4728-4734.

,,--- and -2014 : Safe maritime autonomous navigation with COLREGS, using velocity obstacles. IEEE J. Oceanic Eng., 39, 110-119, doi:10.1109/JOE.2013.2254214.

Manley, J., 2008: Unmanned surface vehicles, 15 years of development. OCEANS 2008, IEEE, 1-4, doi:10.1109/ OCEANS.2008.5152052.

— , and S. Willcox, 2010: The wave glider: A new concept for deploying ocean instrumentation. IEEE Instrum. Meas. Mag., 8-13, doi:10.1109/MIM.2010.5669607.

Motwani, A., 2012: A survey of uninhabited surface vehicles. Marine and Industrial Dynamic Analysis, School of Marine Science and Engineering, Plymouth University Tech. Rep. MIDAS.SMSE.2012.TR.2001, 54 pp.

MTR, 2013: Unmanned surface vessels: Locked and loaded for hydrographic missions. Mar. Technol. Rep., 56 (4), 24-35.

NRC, 2005: Autonomous Vehicles in Support of Naval Operations. National Academies Press, 256 pp.

Pascoal, A., C. Silvestre, and P. Oliveira, 2006: Vehicle and mission control of single and multiple autonomous marine robots. Advances in Unmanned Marine Vehicles, G. N. Roberts and R. Sutton, Eds., IET Control Engineering Series, Vol. 69, Institution of Engineering and Technology, Autonomous Undersea Systems Institute, 353-386.

Rajan, K., F. Py, C. McGann, J. Ryan, T. O'Reilly, T. Maughan, and B. Roman, 2009: Onboard adaptive control of AUVs using automated planning and execution. 16th Annual International Symposium on Unmanned Untethered Submersible Technology 2009, Autonomous Undersea Systems Institute, 261-273.

Rudnick, D. T., R. E. Davis, C. C. Eriksen, D. M. Fratantoni, and M. J. Perry, 2004: Underwater gliders for ocean research. Mar. Technol. Soc. J., 38, 48-59.

Spaulding, M. L., and R. L. Swanson, 2008: Circulation and transport dynamics in Narragansett Bay. Science for 
Ecosystem-Based Management: Narragansett Bay in the 21st Century, A. Desbonnet and B. A. Costa-Pierce, Eds., Springer Series on Environmental Management, Springer, 233-280.

Ullman, D. S., and D. L. Codiga, 2010: Characterizing the physical oceanography of coastal waters off Rhode Island, Part 2: New observations of water properties, currents, and waves. Appendix to Rhode Island Ocean Special Area Management Plan 2010, University of Rhode Island, $108 \mathrm{pp}$.
U.S. Coast Guard, 1999: Navigation rules: International-inland. COMDTINST M16672.2D, 216 pp.

Yang, W.-R., C.-Y. Chen, C.-M. Hsu, C.-J. Tseng, and W.-C. Yang, 2011: Multifunctional inshore survey platform with unmanned surface vehicles. Int. J. Autom. Smart Technol., 1, 19-25, doi:10.5875/ausmt.v1i2.122.

Zhang, Y., J. G. Bellingham, and Y. Chao, 2010: Error analysis and sampling strategy design for using fixed or mobile platforms to estimate ocean flux. J. Atmos. Oceanic Technol., 27, 481-506, doi:10.1175/2009JTECHO700.1. 